\title{
Intraspecific variation in body size and shape in an Andean highland anole species, Anolis ventrimaculatus (Squamata: Dactyloidae)
}

\author{
Martha L. Calderón-Espinosa ${ }^{1}$, Angela M. Ortega-León² \& Joan G. Zamora-Abrego ${ }^{3}$ \\ 1. Grupo de Biodiversidad y Sistemática Molecular, Instituto de Ciencias Naturales, Universidad Nacional de Colombia, \\ Sede Bogotá, Colombia; mlcalderone@unal.edu.co \\ 2. Grupo de Biodiversidad, Departamento de Biología, Universidad de Córdoba, Colombia; \\ amortega@sinu.unicordoba.edu.co \\ 3. Grupo de Ecología y Conservación de Fauna Silvestre, Departamento de Ciencias Forestales, Universidad Nacional, \\ Sede Medellín, Colombia; jogzamoraab@unal.edu.co \\ Correspondence author
}

Received 31-X-2011. C Corrected 20-VII-2012. Accepted 20-VIII-2012.

\begin{abstract}
Variation in body characteristics related to lizard locomotion has been poorly studied at the intraspecific level in Anolis species. Local adaptation due to habitat heterogeneity has been reported in some island species. However, studies of mainland species are particularly scarce and suggest different patterns: high variability among highland lizards and poorly differentiated populations in one Amazonian species. We characterized inter population variation of body size and shape in the highland Andean Anolis ventrimaculatus, an endemic species from Western Colombia. A total of 15 morphometric variables were measured in specimens from the reptile collection of the Instituto de Ciencias Naturales, Universidad Nacional, Colombia. The study included individuals from seven different highland localities. We found size and shape sexual dimorphism, both of which varied among localities. Patterns of variation in body proportions among populations were different in both males and females, suggesting that either sexual or natural selective factors are different in each locality and between sexes. Since this species exhibits a fragmented distribution in highlands, genetic divergence may also be a causal factor of the observed variation. Ecological, behavioral, additional morphological as well as phylogenetic data, may help to understand the evolutionary processes behind the geographic patterns found in this species. Rev. Biol. Trop. 61 (1): 255-262. Epub 2013 March 01.
\end{abstract}

Key words: Anolis ventrimaculatus, intraspecific variation, Mainland, South America.

The study of among-species variation of characters involved in locomotion in Anolis species (body size and shape and lamellae number) has revealed different patterns in islands versus continental areas (Irschick et al. 1997, Velazco \& Herrel 2007, Pinto et al. 2008, Schaad \& Poe 2010). These differences suggest that the evolutionary processes that underlie diversity in these morphological characteristics, depend on several selective factors that influence the optimal fit between morphology, behavior and the use of vegetation structure, and that these factors are different in islands versus mainland regions (Macrini et al. 2003, Losos 2009).
The evaluation of intraspecific geographic variation in body proportions is one strategy to identify the selective factors that have influenced evolution of body size. Exploration of morphological variation in some island species like Anolis oculatus from the Lesser Antilles, suggest that habitat heterogeneity may create natural selection pressures that determine, partially, variation in scutellation and body proportions (Malhotra \& Thorpe 1997, Knox et al. 2001, Thorpe et al. 2005), and that selective forces maintain this variation despite homogenizing effects of genetic flux (Stenson et al. 2002). 
Intraspecific variation within South American mainland Anolis is almost unknown. The only species that have been studied in this context are the Andean A. mariarum (Bock et al. 2009) and the Amazonian species A. fuscoauratus (Vitt et al. 2003). Populations of $A$. mariarum from different elevations exhibited substantial variation in body size, body shape and scale counts. In this study, variation was not clearly related to climatic differences among sites. In contrast, A. fuscoauratus from the Amazon, exhibited little morphological variation (Vitt et al. 2003) even when the study sites varied in number of Anolis species and total lizard species community composition. In this species, minor morphological variation mirrors low genetic divergence (Glor et al. 2001).

Anolis ventrimaculatus is a mainland highland endemic species from Western Colombia, and exhibits a fragmented distribution throughout the mountains of the Western Cordillera (Ayala \& Castro, unpublished). According to Ayala \& Castro, this species inhabits dense and shady vegetation in temperate, humid sites, and is usually observed climbing on thick ferns. At a broad geographic scale, it seems that this species occurs only in lower montane wet forest, but there is no detailed ecological information about variation in local habitat structure and we do not know if there is local variation in microhabitat use. Based on studies of other Anolis distributed across the same area (Castro \& Ayala, unpublished), it seems that lizard community composition is variable among sites where $A$. ventrimaculatus occurs, and that ecological interactions could be different at each site. The present study aims to characterize geographic variation in body dimensions within this species in order to detect local patterns, and to offer hypotheses as to what factors might have driven the evolution of body proportions in high Andean anoles.

\section{MATHERIALS AND METHODS}

Sampled localities and morphological data: We examined preserved specimens of the reptile collection (Colecciones Zoológicas-Área
Reptiles) of the Instituto de Ciencias Naturales, Universidad Nacional, Colombia. The studied organisms came from seven different populations of Anolis ventrimaculatus that were separated by a minimum of $9.65 \mathrm{~km}$ up to $272 \mathrm{~km}$ (maximum) in a straight-line distance. Sampled localities included in this study were: 1-Antioquia, Frontino-Nutibara and Urrao, $\mathrm{n}=38$, (ICN-R 9244-49, 9251, 9254, 9257, 9335-44, 9346-53); 2-Valle del Cauca, El Cairo, $n=25$, (ICN-R 9350-62, 9364-68, 9370, 9373, 968993); 3-Risaralda, Mistrató, n=15, (ICN-R 970713, 9716-19, 9721-22, 9724, 9727); 4-Valle del Cauca, Lago Calima, n=16, (ICN-R 3540-55); 5-Quindío, Calarcá-Filandia, $\mathrm{n}=14$, (ICN-R 5790, 5792-96, 9693-96, 9698, 9700, 970306); 6-Valle del Cauca, Peñas Blancas, $\mathrm{n}=19$ (ICN-R 3555-74, 9333); 7-Risaralda, Pueblo Rico, $n=17$, (ICN-R 9630-40, 9649-54)]. Elevations for localities oscillated from 1140 to $2225 \mathrm{~m}$. A total of 144 adult $A$. ventrimaculatus were analyzed: 57 males and 87 females.

Data for 15 morphometric variables were obtained with a digital caliper (precision $0.1 \mathrm{~mm}$ ), as follows: (1) Snout Vent Length(SVL): from the tip of the nose to the posterior end of the cloaca, (2) Trunk length: distance between the axilla and the groin, (3) Tail length: from the base of the tail to the distal end, (4) Humerus length: from the insertion to the pectoral girdle to the elbow, (5) Ulna length: from the elbow to the center of the wrist, (6) Metacarpus length: from the center of the wrist to the base of the IV finger, (7) Femur length: from the insertion of the pelvic girdle to the knee, (8) Tibia Length: from the knee to the base of the foot, (9) Metatarsus length: from the posterior end of the foot to the base of the IV toe, (10) Toe length: from the base of the IV toe insertion to its tip, including the fingernail, (11) Lamella number: under the second and third phalanges of the fourth toe, (12) Head Length: from the posterior end of the jaw to the tip of the nose, (13) Head Width: at the widest point of the head from a dorsal view, (14) Head Depth: at the highest point of the head from a lateral view, and (15) Length of mouth opening: from the tip of the rostral scale to the joint 
between last supra and infra labial scales. Most measurements were taken by one of the authors (G.Z) with the exception of $A$. ventrimaculatus from Pueblo Rico $(\mathrm{n}=17)$; in this case, a second measurement was taken from a random sample of individuals measured by G.Z.; the variation between the two measurements averaged less than $5 \%$. All variables were $\log ^{10}$ transformed before all subsequent analyses. Size effect was removed through regression analyses of log SVL on each log transformed morphometric variable.

Sexual dimorphism: We used averaged snout vent length (SVL) of adult lizards to estimate Sexual Size Dimorphism index (SSDi) according to the equation:

$\mathrm{SSDi}=(\mathrm{SVL}$ of the larger sex/SVL of the smaller sex $)-1$

We expressed this value as positive if females were larger and negative if males were larger (Lovich \& Gibbons 1992). Additionally, we compared body size between males and females through t-tests.

We also explored sexual shape dimorphism. Body dimension proportions (each variable value/SVL) were compared between sexes and among localities, through MANOVA analysis. We also evaluated shape and size dimorphism within the two localities (FrontinoNutibara and Urrao-El Cairo, localities one and two, respectively) that had the highest sample sizes.

Within species variation: We performed multivariate tests to describe geographic variation in morphometric characters of $A$. ventrimaculatus. Males and females were analyzed separately. We used principal component analysis (PCA) followed by discriminant function analyses (DFA) to describe and test within species variation. All statistical tests were performed in Statistica v. 4.0.

\section{RESULTS}

Sexual size dimorphism: Anolis ventrimaculatus exhibited sexual size dimorphism, and males showed the largest sizes $(n=144$, $\mathrm{t}=-9.7006, \mathrm{p}<0.0001)$ (Table 1). SSDi differed among localities ( -2.077 to -2.31$)$, and this apparent variation might be related to the variation observed in female body size among

TABLE1

Mean variable values for $A$. ventrimaculatus

\begin{tabular}{lcc}
\multicolumn{1}{c}{ Variable name } & Males (Mean $\pm \mathrm{SD})$ & Females $($ Mean $\pm \mathrm{SD})$ \\
\hline SVL $^{* 1,2}$ & $\mathrm{n}=57$ & $\mathrm{n}=87$ \\
Trunk length*2 $^{*}$ & $70.8 \pm 6.57$ & $59.94 \pm 5.62$ \\
Humerus length $^{1}$ & $28.28 \pm 3.12$ & $24.96 \pm 2.92$ \\
Ulna length & $13.96 \pm 1.54$ & $11.71 \pm 1.14$ \\
Metacarpus length $^{2}$ & $11.84 \pm 1.41$ & $9.83 \pm 1$ \\
Femur length & $3.02 \pm 0.44$ & $2.53 \pm 0.34$ \\
Tibia length*2 & $21.06 \pm 2.11$ & $17.88 \pm 1.76$ \\
Metatarsum length & $19.27 \pm 1.77$ & $16.39 \pm 1.45$ \\
IV toe length*2 & $10.63 \pm 1.07$ & $9.04 \pm 1.01$ \\
Head length*1 & $17.47 \pm 1.39$ & $14.77 \pm 1.39$ \\
Head width* & $16.73 \pm 2.15$ & $14.68 \pm 1.18$ \\
Head deep*2 & $10.53 \pm 0.98$ & $9.13 \pm 0.78$ \\
Lamella number*2 & $8.75 \pm 0.82$ & $7.41 \pm 0.63$ \\
Tail length & $19.67 \pm 1.09$ & $19.17 \pm 1.17$ \\
\hline
\end{tabular}

* Statistically significant different variables $(\mathrm{p}<0.05)$ between sexes (pooled data of all localities), 1 and 2 indicate variables that differ in locality one and two respectively. Measurements are given in $\mathrm{mm}$. 
populations (see below). The same pattern of SSD, with males larger than females, was recovered within the two localities that were evaluated (Table 1).

Shape dimorphism: Analysis of pooled data from all localities indicated that head height, trunk length and toe length and lamella number varied between males and females of $A$. ventrimaculatus, after removing the effects of body size (Table 1). MANOVA results revealed that most morphometric variables were different among localities $\left(\mathrm{F}_{78}=6.78, \mathrm{p}<0.001\right)$, some were different between sexes $\left(\mathrm{F}_{13}=9.17\right.$, $\mathrm{p}<0.001$ ), and there was a significant interaction between sex and locality $\left(\mathrm{F}_{78}=4.81\right.$, $\mathrm{p}<0.001$ ), suggesting that patterns of sexual dimorphism also varied among localities. A $t$ test of residuals of each variable within the two evaluated localities revealed that patterns of sexual differences in body proportions varied between localities. In locality one, sexes were dimorphic in head $(\mathrm{t}=-262765, \mathrm{p}<0.05)$ and humerus length $(\mathrm{t}=-248342, \mathrm{p}<0.05)$ (larger in males). Sex differences in locality two included trunk length $(\mathrm{t}=2718861, \mathrm{p}<0.05)$ (larger in females), head length $(\mathrm{t}=-432121, \mathrm{p}<0.05)$, height $(\mathrm{t}=-210117, \mathrm{p}<0.05)$, length of mouth opening $(\mathrm{t}=-298496, \mathrm{p}<0.05)$, metacarpus $(\mathrm{t}=$ $266225, \mathrm{p}<0.05)$, fourth toe length $(\mathrm{t}=-215446$, $\mathrm{p}<0.05$ ) (all larger in males), and lamellae number $(\mathrm{t}=-296365, \mathrm{p}<0.01)$ (slightly more in males) (Table 1).

Within species variation: Geographic variation was evaluated independently for males and females due to sexual dimorphism.

Interlocality variation of body size was not observed in males of $A$. ventrimaculatus $(\mathrm{F}=1.5, \mathrm{p}>0.05, \mathrm{n}=57)$, but variation in female SVL was marginally significant $(\mathrm{F}=2.2$, $\mathrm{p}=0.045, \mathrm{n}=87$ ).

Geographic variation in other characteristics was observed for both males and females after removing body size effect. Females from locality 7 (Pueblo Rico) formed a distinctive group under PCA analysis (Fig. 1). Five principal component analysis was required to explain $80 \%$ of the variation (Table 2). Toe length, femur length, head length, lamellae number and humerus length were the variables with highest load on each component, respectively. Individuals from this locality were correctly assigned with 99 to $100 \%$ assignation probabilities,

TABLE 2

PCA for $A$. ventrimaculatus females

\begin{tabular}{lccccc}
\multicolumn{1}{c}{ Variables } & PC1 & PC2 & PC3 & PC4 & PC5 \\
Head deep & 0.109906 & 0.087493 & 0.010836 & 0.068011 & 0.024036 \\
Head width & 0.132854 & 0.106204 & 0.000070 & 0.067787 & 0.000674 \\
Head length & 0.026766 & 0.023334 & 0.386808 & 0.020234 & 0.003305 \\
Opening mouth length & 0.001653 & 0.004450 & $\mathbf{0 . 4 3 2 3 6 4}$ & 0.001774 & 0.059717 \\
Trunk length & 0.077331 & 0.012591 & 0.015936 & 0.106977 & 0.391060 \\
Humerus length & 0.025103 & 0.176740 & 0.006504 & 0.021801 & $\mathbf{0 . 1 6 7 0 8 1}$ \\
Ulna length & 0.143073 & 0.060025 & 0.000089 & 0.000347 & 0.002751 \\
Metacarpus length & 0.066988 & 0.106187 & 0.048203 & 0.004175 & 0.076084 \\
Femur length & 0.002675 & $\mathbf{0 . 2 1 8 7 8 6}$ & 0.001842 & 0.084817 & 0.154435 \\
Tibia length & 0.096846 & 0.198740 & 0.003962 & 0.005221 & 0.004218 \\
Metatarsum length & 0.143685 & 0.000105 & 0.055208 & 0.009963 & 0.000001 \\
IV toe length & $\mathbf{0 . 1 6 5 6 4 3}$ & 0.003844 & 0.021290 & 0.050511 & 0.020305 \\
Lamellae number & 0.007478 & 0.001502 & 0.016889 & $\mathbf{0 . 5 5 8 3 8 2}$ & 0.096332 \\
Eigenvalue & 36.76 & 22.04 & 16.80 & 11.53 & 8.51 \\
\% Variance & 28.27 & 16.95 & 12.92 & 8.87 & 6.555 \\
\hline
\end{tabular}

Bold numbers represent highest loaded variable on each component. 

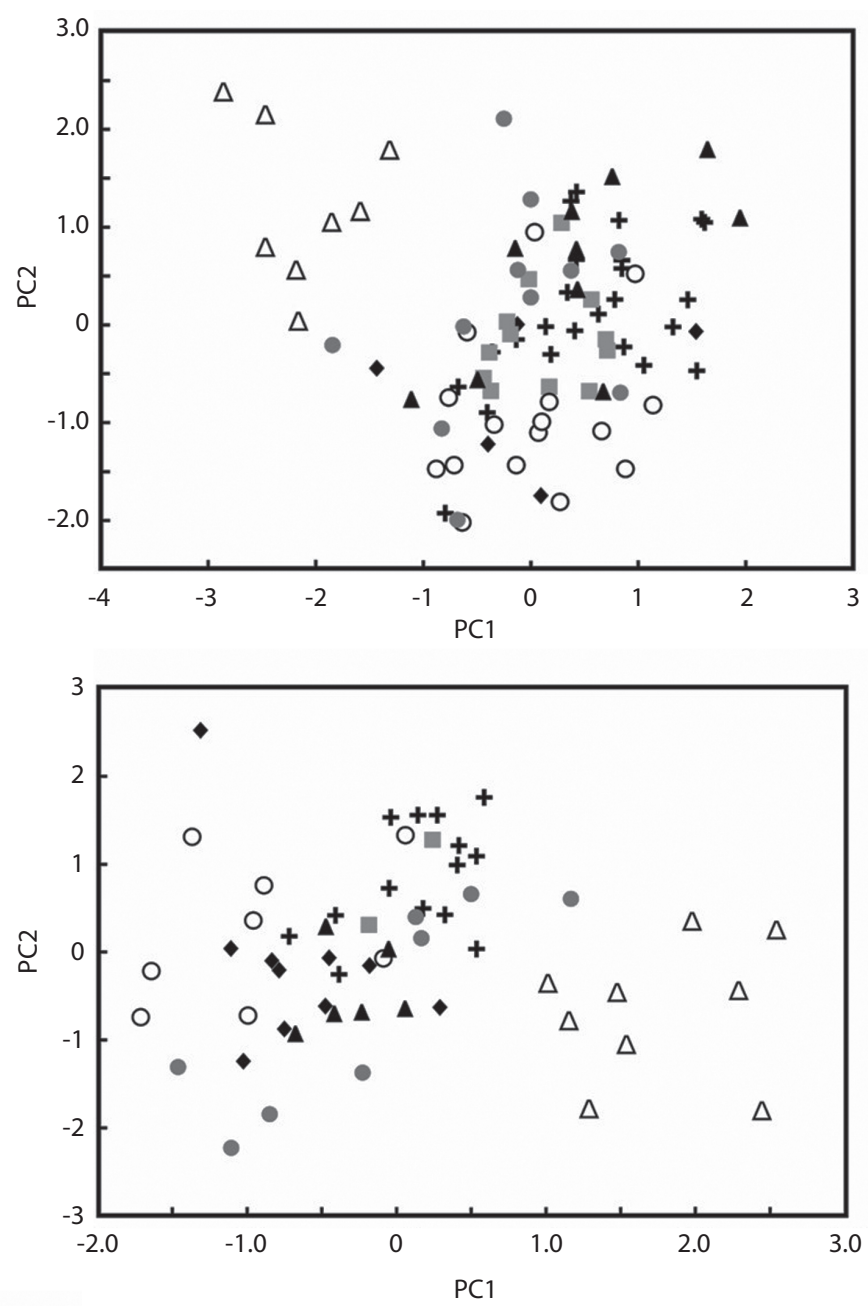

Fig. 1. Morphological variation within $A$. ventrimaculatus females (1A) and males (1B). (+) Locality $1,(\circ)$ locality 2 , locality $3,(\boldsymbol{\Delta})$ locality $4,(\square)$ locality $5,(\bullet)$ locality $6,(\triangle)$ locality 7 .

based on DFA analysis. Minor variation exists among other localitied assignation probabilities to these localities ranged from 4 to $98 \%$.

Males also exhibited geographic variation (Fig. 1). Six principal components were required to explain $80 \%$ of the variation (Table 3 ). Length of head, toe, femur, tibia, metacarpus, and mouth opening were highest loading variables on each component, respectively. Apparently, males exhibited higher variation than females, as was visualized in PCA graphs, with individuals from locality 7 , but also from other localities, segregating in quite well defined groups. DFA analysis supported this observation, since all individuals from localities, 2, 3 and 7 were correctly grouped with relatively high assignation probabilities (100\% to locality 7 , and $47-99 \%$ in other localities).

\section{DISCUSSION}

Sexual size and shape dimorphism: Sexual dimorphism, with males larger than females, can be explained through three 
TABLE 3

PCA for $A$. ventrimaculatus males

\begin{tabular}{lcccccc}
\multicolumn{1}{c}{ Variables } & PC1 & PC2 & PC3 & PC4 & PC5 & PC6 \\
Head deep & 0.205582 & 0.005008 & 0.026722 & 0.000933 & 0.017658 & 0.006804 \\
Head width & $\mathbf{0 . 2 2 8 3 1 0}$ & 0.001392 & 0.073421 & 0.011636 & 0.010124 & 0.008669 \\
Head length & 0.227238 & 0.025555 & 0.000414 & 0.016405 & 0.009463 & 0.009002 \\
Opening mouth length & 0.017828 & 0.064966 & 0.000801 & 0.031009 & 0.170215 & $\mathbf{0 . 6 4 3 8 5 8}$ \\
Trunk length & 0.167163 & 0.000577 & 0.027519 & 0.051508 & 0.041691 & 0.078805 \\
Humerus length & 0.000729 & 0.217405 & 0.070057 & 0.070657 & 0.030427 & 0.024883 \\
Ulna length & 0.000070 & 0.204280 & 0.003833 & 0.220008 & 0.005222 & 0.004218 \\
Metacarpus length & 0.066926 & 0.072616 & 0.004832 & 0.065130 & $\mathbf{0 . 2 7 0 9 9 2}$ & 0.094466 \\
Femur length & 0.036613 & 0.020930 & $\mathbf{0 . 3 6 4 7 4 3}$ & 0.016154 & 0.058395 & 0.018713 \\
Tibia length & 0.040718 & 0.006358 & 0.051398 & $\mathbf{0 . 3 0 0 4 0 0}$ & 0.169310 & 0.008962 \\
Metatarsum length & 0.000507 & 0.151008 & 0.039230 & 0.174499 & 0.015215 & 0.000962 \\
IV toe length & 0.000001 & $\mathbf{0 . 2 1 5 2 9 3}$ & 0.014775 & 0.010345 & 0.076600 & 0.073106 \\
Lamellae number & 0.008314 & 0.014613 & 0.322256 & 0.031315 & 0.124688 & 0.027554 \\
Eigenvalue & 31.74 & 25.05 & 15.60 & 15.06 & 9.65 & 8.35 \\
\% Variance & 24.41 & 19.27 & 12 & 11.58 & 7.43 & 6.42 \\
\hline
\end{tabular}

different evolutionary scenarios: sexual selection, intersexual niche divergence and differences in reproductive roles (Darwin 1859, 1871, in Butler \& Losos 2002). Males of $A$. ventrimaculatus are territorial (Kattan 1984) suggesting that male competition could drive sexual differences observed in body size.

Shape dimorphism also occurs in this species and seems to involve different characteristics at each locality. This result suggests that a plethora of factors could be affecting intersexual interaction and that they may vary at each locality. Variation in intersexual interactions would be then translated into variation in microhabitat use between males and females among localities. Since microhabitat use (movement through vegetation structure) is influenced by body size and shape, a necessary result would be different degrees of sexual dimorphism in these characteristics among localities.

Geographic intraspecific variation in body size and body shape dimorphism in Anolis has not been widely explored. Cox \& Calsbeek (2009) described variation in sexual size dimorphism in A. sagrei, and concluded that it is not explained by geographical variation in sexual selection forces, but by differences in environmental requirements that affect male growth rates. Interspecific interactions may also influence the degree of sexual dimorphism in Anolis (Losos 2009), therefore it is possible that differences in community composition at each locality where $A$. ventrimaculatus occurs, have a local affect on resource partitioning and then, generate geographic variation in those selective forces that drive sexual dimorphism evolution in this species. Nevertheless, the causes underlying variation in $A$. ventrimaculatus sexual dimorphism are unknown.

Geographic variation: Phenotypic variation within $A$. ventrimaculatus was characterized and exhibited quite different patterns within males and females. Variation seemed to be higher in males, and involved more body variables than in females. In both sexes, individuals from locality 7 (Pueblo Rico) appeared as the most differentiated. Variation in head dimensions may be explained under different scenarios involving sexual selection or natural selection. Preliminary observations suggest that individuals from the localities sampled all feed on the same items (Barragán \& CalderónEspinosa, unpublished), but it is unknown if there are differences in prey size among 
localities. If so, this could be related to variation in head length in both sexes and in mouth opening in males. However, head dimensions may also vary due to differential male-male interactions at each locality.

Variation in those body variables related to habitat use or locomotion (limb length and lamellae number) could be the result of local divergence in habitat use. Unfortunately, ecological and behavioral data for this species are very scarce. Nocturnal perch use has been described for a single population of $A$. ventrimaculatus (Kattan 1984), and diurnal habitat use has not been studied in detail, although some observations suggest that $A$. ventrimaculatus can be considered as a small bush and fern climber (Ayala \& Castro, unpublished). Given that the localities where these lizards were captured apparently have the same vegetation type (lower montane wet forest), should future studies reveal variation in habitat use among populations, we would expect this variation to be explained by differences in the lizard communities at each site. If our prediction is correct, community composition would be interpreted as the primary influence on $A$. ventrimaculatus behavior and morphology, rather than differences in habitat structure. However, minor variation in vegetation type, and thus in habitat structure is also possible. These are two main aspects to be explored within the distributional range of this species. Additionally, it should be noted that $A$. ventrimaculatus exhibits a fragmented distribution across its range, thus, it is also possible that genetic divergence has played its part as a causative agent of the morphometric variation observed.

At the present time data are lacking to corroborate any of our hypothesis about causes of underlying variation in body size dimensions in this species, but the patterns detected here form a baseline to direct further studies.

\section{ACKNOWLEDGMENTS}

We thank A. Barragán for helping us with measurements of some individuals. D. Irschick, R. Moreno and five anonymous reviewers made very helpful comments that improved this manuscript. L. Raz corrected the English writing of the manuscript.

\section{RESUMEN}

La diversificación fenotípica al interior de una especie en características de dimensiones corporales relacionadas con la locomoción de los lagartos, se ha estudiado poco en especies de Anolis. Los datos de algunas especies de isla revelan patrones distintos de variación geográfica y sugieren que la adaptación local, debida a la heterogeneidad del hábitat, ocurre a este nivel. Los estudios de especies de continente son particularmente escasos y sugieren patrones distintos: un lagarto altoandino altamente variable y poblaciones poco diferenciadas en una especie amazónica. Caracterizamos la variación inter poblacional en el tamaño y forma del cuerpo del lagarto altoandino Anolis ventrimaculatus, especie endémica del Oeste de Colombia. Encontramos variación geográfica en el dimorfismo sexual en tamaño y forma. El patrón de variación en las proporciones corporales entre poblaciones fue distinto en machos y en hembras, sugiriendo que las presiones de selección sexual o natural son diferentes en cada localidad. Dado que la especie exhibe una distribución fragmentada en alta montaña, la divergencia genética entre poblaciones puede ser otro factor causal de la variación observada. Datos ecológicos, etológicos y morfológicos adicionales, así como información filogenética puede contribuir al entendimiento de los procesos evolutivos responsables del patrón de variación geográfica encontrado en esta especie.

Palabras clave: Anolis ventrimaculatus, variación intraespecífica, continente, Sur América.

\section{REFERENCES}

Bock, B.C., A.M. Ortega, A.M. Zapata \& V. Páez. 2009. Microgeographic body size variation in a high elevation Andean anole (Anolis mariarum, Squamata, Polychrotidae). Rev. Biol. Trop. 57: 1253-1262.

Butler, M.A. \& J.B. Losos. 2002. Multivariate sexual dimorphism, sexual selection and adaptation in Greater Antilles Anolis lizards. Ecol. Monograph. 72: 541-559.

Cox, R.M. \& R. Calsbeek. 2009. Sex specific selection and intraspecific variation in sexual size dimorphism. Evolution 64: 798-809.

Darwin, C. 1859. On the origin of species by means of natural selection, or the preservation of favoured races in the struggle for life. John Murray, London, United Kingdom.

Darwin, C. 1871. The descent of man and selection in relation to sex. John Murray, London, United Kingdom. 
Glor, R.E., L.J. Vitt \& A. Larson. 2001. A molecular phylogenetic analysis of diversification in Amazonian Anolis lizards. Mol. Ecol. 10: 2661-2668.

Irschick, D., L.J. Vitt, P.A. Zani \& J.B. Losos. 1997. A comparison of evolutionary radiations in mainland and Caribbean Anolis lizards. Ecology 78: 2191-2203.

Kattan, G. 1984. Sleeping perch selection in the lizard Anolis ventrimaculatus. Biotropica 16: 328-329.

Knox, A.K., J.B. Losos \& C.J. Schneider. 2001. Adaptive radiation versus intraspecific differentiation: morphological variation Caribbean Anolis lizards. J. Evol. Biol. 14: 904-909.

Losos, J.B. 2009. Lizards in an evolutionary tree. University of California, Berkeley, USA.

Lovich, J.E. \& J.W. Gibbons. 1992. A review of techniques for quantifying sexual size dimorphism. Growth Develop. Aging 56: 269-281.

Macrini, T.E., D.J. Irschick \& J.B. Losos. 2003. Ecomorphological differences in toepad characteristics between Mainland and Island Anoles. J. Herpetol. 37: 52-58.

Malhotra, A. \& R. Thorpe. 1997. Size and shape variation in a Lesser Antillean anole Anolis oculatus (Sauria: Iguanidae), in relation to habitat. Biol. J. Lin. Soc. 60: 53-72.
Pinto, G., D.L. Mahler, L.J. Harmon \& J.B. Losos. 2008. Testing the island effect in adaptive radiation: rates and patterns of morphological diversification in Caribbean and mainland Anolis lizards. Proc. R. Soc. B 275: 2947-2757.

Schaad, E. \& S. Poe. 2010. Patterns of ecomorphological convergence among mainland and island Anolis lizards. Biol. J. Lin. Soc. 101: 852-859.

Stenson, A.G., A. Malhotra \& R.S. Thorpe. 2002. Population differentiation and nuclear gene flow in the Dominican anole (Anolis oculatus). Mol. Ecol. 11: 1679-1688

Thorpe, R.S., J.T. Reardon \& A. Malhotra. 2005. Common Garden and Natural Selection Experiments Support Ecotypic Differentiation in the Dominican Anole (Anolis oculatus). Am. Nat. 165: 495-504.

Velazco, J.A. \& A. Herrel. 2007. Ecomorphology of Anolis lizards of the Choco' region in Colombia and comparisons with Greater Antillean ecomorphs. Biol. J. Lin. Soc. 92: 29-39.

Vitt, L., T.C.S. Avila-Pires, P.A. Zani, S.S. Sartorius \& M.C. Espósito. 2003. Life above ground: ecology of Anolis fuscoauratus in the Amazon rain forest, and comparisons with its nearest relatives. Can. J. Zool. 81: 142-156. 